\title{
EL DISCURSO HETEROLÓGICO EN EL TEATRO DE LOPE DE VEGA \\ (Aproximación a las funciones del escrito)
}

Antonio Garrido Domínguez

Universidad Complutense

\section{O. INTRODUCCION}

La abundante producción de Lope ha sido objeto de múltiples estudios, que se interesan, preferentemente, por las fuentes, estructura y significado histórico-literario de sus dramas. Existe, sin embargo, un aspecto que al parecer no ha recibido la suficiente consideración, pasando de hecho reiteradamente inadvertido ante los ojos de los investigadores. Me refiero a aquellos elementos introducidos en el drama bajo la forma de escrito y que son leídos en escena. Es un procedimiento tan reiterado en el teatro de Lope -el número de piezas en que no aparece ningún escrito es relativamente muy bajo, si se tiene en cuenta que en algunas se presentan hasta cinco- que merece, obviamente, una consideración más atenta.

El objeto de este estudio es doble: reunir y describir, en primer lugar, la mayoría de los escritos que se encuentran en los dramas de Lope y, en segundo término, analizar su cometido. La perspectiva metodológica del trabajo es predominantemente formal-funcional, pero en ella adquieren especial preponderancia los puntos de vista de $\mathbf{M}$. Bajtín respecto de los géneros intercalares y su contribución al plurilingüismo de la expresión literaria.

\section{Los Géneros Escritos como Géneros InTERCALARES}

La concepción de la actividad lingüística general $-y$ de la literaria, en particular- como realidad esencialmente heteroglósica se debe de 
manera especial a M. Bajtín ${ }^{1}$. De acuerdo con sus puntos de vista, la operación de hablar consiste en un intercambio de discursos entre los participantes en el acto comunicativo. Esto quiere decir que el discurso propio se elabora a partir de las reacciones de los demás hacia él y, también, de la integración de discursos ajenos. En otras palabras: el discurso propio es una realidad poblada de citas -unas más evidentes, otras más difíciles de percibir a primera vista- de otros discursos. Así pues es la incorporación de los enunciados ajenos lo que permite la constitución del enunciado propio, tanto en los géneros primarios como secundarios.

En cuanto género secundario, la literatura manifiesta en su grado más alto -si se exceptúan los géneros poéticos, y no todos- el carácter heterológico -polifónico- de toda actividad lingüística. Escribir es una tarea eminentemente parasitaria: el escritor se apropia de las palabras de otros para sus fines particulares. Este hecho tiene repercusiones muy importantes sobre el discurso propio y sobre el ajeno. La primera es que, al insertarse en un contexto nuevo, las palabras de otro experimentan modificaciones (con frecuencia) sustanciales: suenan de modo diferente, ya que, por lo general, responden a intenciones también diferentes. En segundo lugar, la lengua del escritor -cuya misión consiste en orquestar las distintas voces que aparecen en su interior- se ve enriquecida desde múltiples puntos de vista: formal, léxica, ideológicamente ...

Dentro de la literatura -particularmente, en el interior de la novela- los discursos ajenos adoptan diferentes formas: narraciones, discursos filosóficos, morales o eruditos, cartas, diarios ... En realidad, todos los géneros característicos de la comunicación diaria, oral o escrita, son susceptibles de ser representados literariamente. Lo que varía es la forma concreta de la representación. El discurso propio y ajeno pueden, por ejemplo, amalgamarse, formando un todo en el que no resulta fácil deslindar en cada momento a quién corresponde la iniciativa. Otras posibilidades son la representación por medio de diálogos o la incorporación respetuosa del discurso ajeno (cuya integridad material se ve preservada por la presencia de las comillas).

En el primer caso, siempre es posible hablar de dos lenguas: la representante -que explica, aclara y crea una imagen irónica, paródica, etc., de otra lengua- y la representada. En el segundo caso el escritor evidencia sus intenciones a través de los diálogos de los personajes, sin confundirse con ellos. La tercera modalidad resulta de especial importancia para los propósitos del presente trabajo. Se refiere a la incorpo-

1 Las ideas que siguen proceden de "El problema de los géneros discursivos", Estética de la creación verbal (México: Siglo XXI, 1982), pp. 248-293, y, también, de "Du discours romanesque", Esthétique et téorie du roman (París, Gallimard, 1978), pp. 83-233. 
ración de discursos ajenos sin perder sus perfiles diferenciales. Por lo general, en este caso las comillas garantizan el respeto a la forma externa del enunciado ajeno. Los géneros intercalares del teatro de Lope -al menos, los que adoptan la forma de escrito- se acogen en su totalidad a esta tercera posibilidad.

Bajo la apariencia de cartas, billetes o papeles, fundamentalmente, Lope introduce en su teatro numerosos géneros de la comunicación cotidiana o cultural, que desempeñan -como se verá posteriormentefunciones de gran relevancia en el desarrollo de los dramas ${ }^{2}$. A continuación se ofrece, en primer lugar, el recuento de los géneros intercalares, realizado sobre el corpus de comedias que Morley y Bruerton dan como seguras de Lope ${ }^{3}$. Sigue una descripción relativamente amplia de las peculiaridades de los diferentes géneros: su procedencia, procedimientos de integración y expresividad; la recepción y los aspectos material, formal y referencial; imágenes del emisor y del destinatario; figuras del proceso amoroso ... Se reserva para el último lugar el análisis de las funciones del escrito.

\section{Descripcion De Los Generos Intercalares ${ }^{4}$}

\subsection{La declaración amorosa (confesión)}

Es extremadamente abundante y se manifiesta, preferentemente, a través del verso ${ }^{6}$. Se presenta, por lo general, asociada a la expresión amorosa. Ofrece como rasgos característicos los deícticos personales,

2 El uso que hace Lope de los términos billete, carta y papel concuerda plenamente con la definición académica. El billete aparece relacionado con el recado y la poca trascendencia de los asuntos. En la carta, por el contrario, resalta el carácter secreto del contenido y, por eso, va cerrada -a diferencia del billete. En el papel, finalmente, destaca la extensión- notablemente mayor -y la heterogeneidad de los contenidos (Cfr. RAE: Diccionario de Autoridades -Madrid - Gredos, 1969-, s.v.respectivas).

3 Cfr. S.G. Morley y C. Bruerton: Cronología de las comedias de Lope de Vega (Madrid: Gredos, 1969). El estudio incluye, además, algunas dudosas como La Estrella de Sevilla.

- Agradezco al profesor Lázaro Mora la cesión desinteresada de no pocos de los textos a los que se hace referencia en el presente estudio.

5 (B)iblioteca de (A)utores (E)spañoles (Madrid, Atlas, 1950), XXIV, pp. 344-45. Los volúmenes numerados con romanos corresponden a las ediciones de Obras y Comedias Escogidas, publicadas por la BAE; los designados con arabigos, por el contrario, se refieren a los tomos editados por la Real Academia de la Lengua.

6 Por razones de espacio no es posible ofrecer una muestra de cada género intercalar. Por ello, la exposición se limita a una simple descripción. 
el empleo preponderante del presente y la acentuación del carácter lírico del discurso. El lenguaje recoge toda la imaginería renacentista e incorpora los nuevos modos de los estilos culterano y conceptista (en proporción menor, naturalmente). Aparecen, por lo general, sin firma. El perro del hortelano ${ }^{5}$ ofrece un ejemplo bastante ilustrativo de declaración amorosa $(X X I V, 344-345)^{7}$.

\subsection{La confidencia}

Aunque genérica y semánticamente emparentada con la declaración, en la confidencia destaca el carácter secreto, oculto, de la información que se transmite. Predomina en dramas de enredo y aparece, generalmente, sin firma. Sirven para la comunicación entre los amantes o miembros de la familia. Su lenguaje es eminentemente expositivo y emplea indistintamente la prosa o el verso. A través de la confidencia se revelan hechos consumados o se evidencian las intenciones de un determinado personaje. Puede acompañarse de la petición. Uno de los ejemplos más ilustrativos aparece en los Prados de León ${ }^{8}$. Se trata de uno de los géneros mejor representados en el teatro de Lope ${ }^{9}$.

\subsection{La petición}

Su contenido es muy heterogéneo: se utiliza para instar ayuda, solucionar un negocio, saldar una deuda; se pide clemencia, consejo, socorro, mediación en el amor, una entrevista, la intervención real, etc. En los géneros de carácter jurídico la petición puede confundirse con la orden - cuando la persona que pide es de rango superior. Asimismo la petición se alía frecuentemente con la promesa o la amenaza. Dentro de ella se distinguen, por lo general, dos partes: la exposición del asunto y la petición propiamente dicha. En la primera predomina el indicativo -presente o pasado- y en la segunda, la expresión del deseo (y, consiguientemente, el subjuntivo). En los escritos de tipo

7 Otros ejemplos: Virtud, pobreza y mujer, LII, p.223; Dómine Lucas, XXIV, p. 49; El caballero de Olmedo, XXXIV, p. 370; El príncipe perfecto (Primera parte), LII, p. 98; Amar sin saber a quien, XXXIV, p. 446; La Arcadia, XIII, p. 154...

8 LII, p. 446.

9 Más ejemplos: El acero de Madrid, XXIV, p. 366; El despertar a quien duerme, XI, p. 740; El alcaide de Madrid, I, p. 560; La venganza venturosa, X, p. 157; El Hamete de Toledo, VI, pp. 180-181; La villana de Getafe, X, p. 393; Servir a señor discreto, LII, p. 72; La francesilla, V, p. 667; Quien ama no haga fieros, XXIV, p. 435; El desdén vengado, XXXIII, p. $222 \ldots$ 
amoroso la petición y la queja van tan estrechamente unidas que resulta muy difícil precisar con exactitud los límites de cada una. Su extensión es bastante reducida ${ }^{10}$. Una forma especial de la petición es el memorial".

\subsection{El recado (la cita)}

En el recado prima el contenido informativo; su modalidad más importante es la cita. Por lo general, adopta la forma del billete y se caracteriza por la brevedad del enunciado. Pertenecen mayoritariamente al círculo cerrado de los amantes y responde a un deseo de comunicación rápida. Por eso, renuncia a los requisitos formales de la carta (encabezamiento, fecha, firma, etc.); por el contrario, adquieren máxima relevancia las referencias al lugar -jardín, huerto, paseo, reja, puerta ...-, al tiempo -la noche y sus astros son los grandes aliados de los amantes-, a los objetivos que facilitarán el encuentro o el reconocimiento - banda, listón, etc. Por tratarse de un género que se reparte entre lo íntimo y lo familiar se eluden las formas de tratamiento cortés. En este apartado podrían incluirse muchos de los escritos catalogados como declaración, confidencia, promesa o reproche $e^{12}$.

\subsection{La queja y el reproche}

En el dominio amoroso suelen ir juntos. Los amantes se lamentan o echan en cara crueldad o indiferencia y suelen terminar con una petición (de ahí la introducción del imperativo). Se trata de una confesión amorosa velada y, en ocasiones, lleva aneja una amenaza. Literariamente, la queja y el reproche constituyen dos de los géneros en los que la expresión lírica alcanza su nivel más alto. Utiliza un lenguaje

10 La vengadora de las mujeres, XIII, p. 643. La petición aparece en multitud de dramas: El desprecio agradecido, XXXIV, p. 265; Del mal lo menos, IV, p. 475 ; Los embustes de Celauro, XXV, p. 97; El castigo sin venganza, XXV, p. $581 ; E l$ piadoso veneciano, XXIX, p. 406; El villano en su rincón, XXXIV, pp. 149-50. Sobre la concesion, cfr. Los Benavides, XVII, p. $274 \ldots$

11 Cfr. La Estrella de Sevilla, XXIV pp. 145-146.

12 El maestro de danzar, XXXIV, p. 85. También: El marqués de las Navas, LII, p. 504; Amor secreto hasta celos, III, p. 408; El caballero de Olmedo, XXXIV, p. 370; El duque de Viseo, XLI, p. 437; La venganza venturosa, X, p. 157; La discreta enamorada, t. 247. p. 168; El secretario de st mismo, IX, p. 225: El ingrato arrepentido, VI, p. 530; Lo cierto por lo dudoso, XXIV, p. 464; La mocedad de Roldán, XXIX. pp. 15-16; La ventura sin buscalla, X, pp. 283-84; Al pasar del arroyo, XI, p. $248 \ldots$ 
muy rico en figuras e intensamente conceptista. Un buen ejemplo aparece en $; A y$, verdades que en amor ...!, III,p.516 ${ }^{13}$

\subsection{La promesa, el juramento}

Se encuentran, por lo general, vinculados a la tópica amorosa. Ambos miran hacia el futuro, pero difieren en el grado de coacción: mientras la promesa no pasa de una simple afirmación por parte del emisor respecto de su comportamiento, el juramento cuenta con fórmulas que comprometen por entero a la persona. Lingüísticamente, tanto la promesa como el juramento se valen de las formas verbales del presente y del futuro y se concede gran importancia a los nombres del emisor y del destinatario $\mathrm{y}$, también, a la mención del tipo de documento suscrito (cédula, escritura, etc.) ${ }^{14}$.

\subsection{La descripción (el retrato)}

Hace gala de un lenguaje expositivo, en el que predominan el tiempo presente, el uso del adjetivo y las construcciones paralelísticas. Como se veră, la descripción desempeña cometidos de enorme trascendencia para el drama (construcción del personaje, ambientación, etc. $)^{15}$.

\subsection{La relación}

Adopta dos formas fundamentales: la memoria y el memorial. En la primera predomina el carácter meramente expositivo y en el teatro de Lope se asocia, con frecuencia, a la expresión de intenciones. El memorial, por el contrario, constituye, como se ha dicho, una modali-

13 También: De cosario a cosario, XI, p. 662; El casamiento en la muerte, XVII, pp. 87-88; El caballero de Olmedo, XXXIV, p. 370; El principe perfecto (segunda parte), LII, p. 121; La buena guarda, t. 187, p. 66; La niña de Plata, XXIV, p. 282; El valeroso catalán, XIX, p. 178; Los embustes de Celauro, XXIV, pp. 99-100.

14 Cf. Sin secreto no hay amor, XI, p. 165. El ejemplo que sigue corresponde a El desdén vengado, XXXIII, p. 235: "Rugero, Rey de Nápoles, dijo: Que por esta cédula de mi nombre, doy la palabra de casarme con Lisena, Princesa de Bisiñano." Ver, También: Los embustes de Fabia, V, p. 79; Lo que pasa en una tarde, II, p. 304; La fortuna merecida, t. 212, p. 54; Amor secreto hasta celos, III, p. 408...

15 Cf. La pobreza estimada, LII, p. 149 (Se trata sólo de un fragmento de la extensa carta que la protagonista envia a su padre; en ella describe física y moralmente a sus pretendientes). También: La bella Aurora, t. 190, p. 211; El villano en su rincón, XXXIV, p. 139. 
dad de la petición. Se vale de la relación para hacer constar los méritos de un determinado pretendiente. En ambos casos el rasgo lingüístico más sobresaliente es el empleo de estructuras paralelísticas ${ }^{16}$.

\subsection{La condolencia}

La expresión del dolor por cualquier percance se acompaña, normalmente, del ofrecimiento de ayuda -en algunos casos ésta se envía simultáneamente con el pésame- y de una referencia al hecho que ocasionó la desgracia ${ }^{17}$

\subsection{La felicitación}

Coincide, composicionalmente, con la condolencia. Sin embargo, la felicitación brota, a diferencia de aquélla, de un sentimiento de júbilo. Se aproxima al elogio ${ }^{18}$

\subsection{La recomendación}

Incluye tres factores importantes: la presentación de la persona recomendada, exposición de sus méritos y el ruego de que sea atendida. Se trata por todos los medios -incluso la exageración- de influir en la voluntad del destinatario. Predomina el tratamiento de cortesía, ya que, por lo general, se dirige a una persona de rango superior (si se

16 Cf. De cosario a cosario, XI, p. 641; El hijo de Reduan, t. 214, pp. 298-99; Viuda, casada y doncella, X, p. 473. La Estrella de Sevilla ofrece un buen ejemplo de memorial:

"Muy poderoso serior:

Fernán Pérez de Medina veinte años soldado ha sido, y a vuestro padre ha servido. y serviros imagina con su brazo y con su espada, en propios reinos y extraños.

Ha sido adalld diez arias
de la vega de Granada,
Ha estado cautivo en ella
tres anios en ejercicios
cortos; por cuyos oficios
y por su espada que en ella
toda su justicia abona,
pide en este memorial
el bastón de general
de los campos de Archidona".
(XXIV, pp. $145-46)$

$(X X I V, p p .145-46)$

17 Cf. La villana de Getafe, X, p. 381.

18 Cf. El capellán de la Virgen, t. 178, p. 316; Amigo por la fuerza, III, p. 269; La tragedia del rey don Sebastián, t. 225, p. 140; La nueva victoria del Marqués de Santa Cruz, t. 233, p. 203. 
trata de un igual, el recomendante se encuentra, en cualquier caso, en mejor posición $)^{19}$.

\subsection{La excusa}

Se trata de escritos muy breves, en los que destaca el afán del emisor por justificar su actitud o respuesta respecto de una solicitud particular $^{20}$.

\subsection{El consejo}

Reprueba, elogia o trata de orientar el comportamiento del destinatario (hijo, hermano, amante, etc.). La prolijidad de las formas del imperativo se justifica por el carácter exhortativo del mensaje ${ }^{21}$.

\subsection{El desafio}

Destaca la concisión del mensaje y el interés del emisor por dejar muy claros el nombre del destinatario y el lugar y tiempo en que debe celebrarse el duelo. El tratamiento es de cortesía 22.

\subsection{La amenaza}

Por medio de ella se conmina a otra persona a realizar una determinada acción en tiempo breve ${ }^{23}$.

19 Cf. Del mal lo menos, IV, p. 443; El arenal de Sevilla, XI, p. 388; El alcalde mayor, LII, p. 54; Servir con mala estrella, LIII, pp. 47-48; El desprecio agradecido, XXXIV, p. 257; El mayor imposible, XXXIV, p. 474; Amor secreto hasta celos, III, p. 240; La piedad ejecutada, VIII, p. 469.

20

Cf. La prueba de los amigos, XI, p. 127; La Felisarda, V, p. 526.

21

Cf. Sembrar en buena tierra, IX, p. 405; El duque de Viseo, XLI, p. 437; La pobreza estimada, LII, p. 149; Santiago el Verde, XXXIV, p. 195; El primer Fajardo, t. 213, p. 184.

Cf. El grao de Valencia, I, p. 535; La desdichada Estefania, XIX, p. 90; La boda de dos maridos, t. 247, p. 449; El valiente Céspedes, t. 224, p. 89; La envidia de la nobleza, XXIII, p. 169; El blasón de los Chaves de Villalba, t. 215, p. 272...

23

Cf. El blasón de los Chaves de Villalba, t. 215, p. 230; Mudanzas de la fortuna y sucesos de don Beltrán de Aragón, VII, p. 610; La historia de Toblas, VIII, p. 91. 


\subsection{La orden}

Es expresión de la voluntad del superior respecto de sus subordinados. De hecho, la inmensa mayoría de las órdenes que aparecen en el teatro de Lope están firmadas por reyes. Los asuntos son muy heterogéneos: delegación temporal del poder, abdicación en favor de un hijo, abono de una deuda, excomunión, entre otros ${ }^{24}$.

\subsection{La profecía}

Género poco frecuente. El único ejemplo registrado se pone en boca de la Virgen y tiene carácter laudatorio. Emparentada con la alegoría ${ }^{25}$.

\subsection{La máxima}

Es un género de gran concentración semántica. Se encuentra emparentado con la defínición y la cita culta y destaca por su carácter sapiencial. Con ella se tiende a modificar el comportamiento de los personajes $^{26}$.

\subsection{La alegoría}

Goza de gran eficacia dramática, ya que introduce siempre un factor de extrañeza. Puede servir -como en el caso presente- para la expresión de lo lírico ${ }^{27}$.

\subsection{El enigma}

Poco frecuente; emparentado con la alegoría ${ }^{28}$.

24 Cf. Las batuecas del duque de Alba, t. 215, pp. 368-369; Mirad a quien alabais, Lll, p. 458; El gran duque de Moscovia, XV, p. 400; La nueva victoria del marqués de Santa Cruz, t. 233, p. 233; El primer Fajardo, t. 213, p. 204; La varona castellana, XIX, p. 18; El mejor alcalde el rey, XXIV, p. 485; El hijo sin padre, VI, p. $330 \ldots$

Cf. La quinta de Florencia, XXXIII, p. 181.

27 Cf. El labrador venturoso, XVIII, p. 160.

28 Cf. Los celos de Rodamonte, XXIX, pp. 259-260. 


\subsection{La glosa}

El ejemplo registrado se refiere al nombre de Leonor y es un puro ejercicio conceptista. En el ejemplo se alía con el reproche y la súplica. ${ }^{29}$.

\subsection{La canción (panegirico)}

Aparece un solo ejemplo (que se ajusta a la tópica de la albanza del soberano) ${ }^{30}$.

\subsection{La inscripcion}

Se registran dos textos: uno en la empuñadura de la espada de Roldán ${ }^{31}$ y otro en la piedra que ha de cubrir la sepultura de Juan Labrador ${ }^{32}$.

\subsection{La reflexion}

Poco frecuente. Se refiere, por lo general, al comportamiento de las personas ${ }^{33}$.

\subsection{El pacto}

Destaca el carácter formulario el enunciado y la elevada fijación del léxico ${ }^{34}$.

29 Cf. El principe perfecto (segunda parte), IV, p. 121.

Cf. Servir a señor discreto, XIX, p. 269.

Cf. Angelica en el Catay, XXIX, pp. 342-343.

Cf. El villano en su rincón, XXXIV, p. 139.

33 Cf. El caballero del Sacramento, XIX, p. 269. Conviene ver, también, el fragmento final del escrito que aparece en $E l$ valor de las mujeres, $X, p .36$, y la cita culta de El enemigo engariado, V, p. 121.

34 Cf. Carlos V en Francia, XXV, p. 360; El casamiento en la muerte, XVIII, p. 59. 
Se utiliza, generalmente, con el fin de lograr la captura de personas o animales (por los que se ofrece recompensa). El grado de fijación es muy elevado ${ }^{35}$.

\subsection{El aviso}

A través del aviso se advierte a una persona de los peligros que le acechan, se le recomienda cautela o se le ofrece ayuda para salir del apuro. Resulta evidente su parentesco con el recado ${ }^{36}$.

\subsection{La denuncia}

Muy poco frecuente. El ejemplo reseñado está relacionado con la intriga amorosa ${ }^{37}$.

\subsection{La sentencia}

Se ajusta, igual que el pacto y otros escritos jurídicos, a los cánones del género ${ }^{38}$.

\subsection{La dedicatoria}

Aparece un solo ejemplo. Es palmario su parentesco con el panegírico ${ }^{39}$.

Cf. El piadoso veneciano, XXXIII, p. 406; Lo que ha de ser, XXXIV, p. 510.

36 Cf. El amante agradecido, III, p. 112; La discreta enamorada, t. 247, p. 168; El valeroso catalán, XIX, p. 226 ...

37 Cf. La comedia de Bamba, XVI, p. 329.

38 Cf. Don Lope de Cardona, IV, p. 687; Las pobrezas de Reinaldos, XXIX, p. 126; El marqués de Mantua, XXIX, pp. 188-89.

39 Cf. Porfiar hasta morir, XLI, p. 104. 


\section{Observaciones Respecto De Los Géneros Intercalares}

3.1. La descripción anterior no pretende ser exhaustiva en lo que se refiere al número de géneros -incluso bajo la forma de escrito-presentes en el teatro de Lope. Aspira únicamente a ofrecer una muestra de los más representativos. La enorme facilidad observada en el discurso teatral de Lope para asimilar discursos ajenos aparece también en el interior de cada género. Como habrá podido constatarse, no pocos de ellos incorporan otros géneros en calidad de elementos subordinados ${ }^{40}$.

Es preciso señalar, también, la estrecha correlación entre los géneros mejor representados -la confidencia, la queja o reproche, la declaración, el recado, etc.- y las comedias de enredo, es decir, las más características del teatro de Lope ${ }^{41}$. Este hecho explica, en gran medida, los cometidos conferidos a cada escrito.

Dado que los distintos géneros descritos se intercalan en el interior del discurso dramático, es especialmente relevante la consideración de los procedimientos de integración utilizados. En el teatro de Lope los diferentes géneros son fácilmente identificables, ya que se presentan protegidos por las comillas. Aparecen, ya desde el principio, como elementos ajenos y anómalos. Textualmente, esta extrañeza se manifiesta de dos maneras: una, fundamental, es la presencia del recurso material de las comillas; otra, la elección de una modalidad del discurso distinta de la empleada hasta el momento.

En este caso los procedimientos más comunes son el recurso a la prosa -preponderante en géneros como el recado, la promesa, la condolencia, la recomendación, el desafío, la orden, el pacto, etc.- o la ruptura con el modelo estrófico dominante. Esta segunda modalidad predomina -aunque no exclusivamente- en aquellos géneros destinados, por su propia naturaleza, a mediar en el círculo cerrado de los amantes (confidencias, quejas, declaraciones ...). En este sentido es frecuente la aparición del soneto $^{42}$, la octava real ${ }^{43}$, la copla

40 En opinión de Bajtín, “...cada género del uso de la lengua elabora sus tipos relativamente estables de enunciados, a los que denominaremos géneros discursivos.

La riqueza y diversidad de los géneros discursivos es inmensa, porque las posibilidades de la actividad humana son inagotables y porque en cada esfera de la praxis existe todo un repertorio de géneros discursivos que se diferencia y crece a medida que se desarrolla y complica la esfera misma". ("El problema...", op. cit., p. 248).

41 Como es sabido, el tema de la honra es preferido a otros por el dramaturgo ("Arte nuevo de hacer comedias en este tiempo", eds. F. Sánchez Escribano y A. Porqueras Mayo, Preceptiva dramática del Siglo de Oro -Madrid: Gredos, 1971-, p. 163).

42 El perro del hortelano, XXIV, pp. 344-45; ;Ay, verdades que en amor...!, III, p. 518; El caballero de Olmedo, XXXIV, p. 376; La dama boba, XXIV, p. 300.

43 El capellán de la Virgen, t. 178, p. 288; Los celos de Rodamonte, XXIX, pp. 259-60. 
castellana $^{44}$, la redondilla ${ }^{45}$, la copla de arte mayor ${ }^{46}$, etc. Conviene señalar, además, que la enorme variedad de metros empleados por Lope es de por sí una importante contribución a la heterología de sus dramas y, también, que el autor utiliza con bastante liberalidad los preceptos del Arte nuevo respecto de la finalidad propia de cada modelo estrófico ${ }^{47}$.

Ahora bien, conviene resaltar que el discurso entrecomillado no es, a pesar de su aislamiento formal, impenetrable, sino que entabla un diálogo de muy variada índole con el discurso del autor. En otras palabras: las comillas no evitan que el discurso contenido en su interior sea traspasado por las intenciones del escritor. El discurso ajeno se presenta formalmente como tal, pero impregnado de una sensibilidad nueva. En el interior de un nuevo discurso los diferentes géneros se recontextualizan y cobran nuevo acento. En definitiva, suenan de un modo especial y potencian la polifonía del discurso teatral (de por sí heterofónico) $)^{48}$.

En unos casos se trata de géneros que ya pertenecen al ámbito de la cultura; son convenciones artísticas y cuentan con una tradición literaria más o menos larga (en este apartado habría que incluir las declaraciones, lamentos, súplicas, etc.). En otros, de formas estandarizadas $^{49}$ de la comunicación escrita no literaria (bandos, juramentos, de-

44 Los embustes de Celauro, XXIV, p. 97; El valeroso catalan, XIX, p. 216.

45 La Reina Juana de Nápoles, XV...

46 Porfiar hasta morir, XLI, p. 104.

47 Sobre la versificación de Lope, ver S.G. Morley y C. Bruerton: Cronología...; Diego Marín: Uso y función de la versificación dramática en Lope de Vega (Valencia: 1962) También: P.N. Dunn: "Some Uses of Sonnets in the Play of Lope de Vega", Bulletin of Hispanic Studies, XXXIV (1957), pp. 213-222.

48 Dice Bajtín: "Pero aquí también es posible una reacentuación de los géneros, que es tan característica de la comunicación discursiva: por ejemplo, la forma genérica del saludo puede ser trasladada de la esfera oficial a la esfera de la comunicación familiar, es decir, es posible que se emplee con una reacentuación paródica o irónica, así como un propósito análogo puede mezclar diversas esferas". ("El problema...", op. cit., p. 269)

49 De la existencia de una retórica muy desarrollada respecto de un número abundante de géneros de la comunicación escrita cotidiana caben pocas dudas, si se tiene en cuenta la importancia adquirida en los siglos XVI y XVII por ciertos manuales epistolares, dirigidos, principalmente, a secretarios de cámara y, de manera particular, a los pretendientes en el amor. Ver, por ejemplo, G. de Tejada: Estilo de escribir cartas mensajeras cortesanamente a diversos fines y conceptos... (Valladolid: 1533); F. Lopez Estrada (ed.): "Un pliego de cartas y coplas para requerir nuevos amores", Revista de Bibliografia Nacional, 6 (1945), pp. 227-239; A. Redondo: "Antonio de Guevara y Diego de San Pedro: Las cartas de amores del Marco Aurelio", Bulletin Hispanique, 78 (1976), pp. 226-239; Antonio de Torquemada: Manual de Escribientes, eds. M.C. de Zamora y A. Zamora Vicente, Boletin de la Real Academia Española. Anejo XXI (1970).

A la luz de estos datos resulta bastante evidente que Lope incorpora a su teatro géneros de uso frecuente dentro de la comunicación cotidiana, si bien es cierto que algunos de ellos contaban ya con una larga tradición literaria (en particular, todo lo referente a los 
nuncias, decretos, etc.). En cualquier caso, son extraídos de su contexto natural e incorporados al drama. Ahora bien, su función varía: a los objetivos y expresividad que le corresponden en cuanto discurso ajeno se añaden los que le imprimen el autor y la naturaleza de la obra de la que pasan a formar parte. Así, el discurso más serio es sometido por el autor a la prueba de la parodia, la ironía, etc., y, como consecuencia, adquiere matices realmente contradictorios respecto de su expresividad original ${ }^{50}$.

Esto se produce, de manera especial, en los géneros convencionalmente más nobles. Un buen ejemplo lo constituye la oda al Marqués de Santa Cruz, que aparece en Servir a señor discreto. Se trata de un género noble que, al ser insertado en un contexto cómico -es utilizado por Girón como treta con el fin de que su amo pueda conquistar a Leonor-, ve alterado radicalmente su carácter intrínseco. No produce un efecto de admiración, invita a la risa ${ }^{51}$. En general, puede decirse que, exceptuados los dramas más serios de Lope como La Estrella de Sevilla, El Duque de Viseo, etc., todos los géneros escritos que aparecen en su teatro se ven afectados por el carácter tragicómico del contexto en que se presentan. Con mucha frecuencia se relacionan con el enredo y este hecho decide finalmente su expresividad. Todos los géneros -en especial, los más serios- se contagian de la comicidad del ambiente dramático.

El contexto modifica la naturaleza de los géneros intercalares en otro sentido: su función respecto de la comunicación diaria se ve fuertemente alterada. Varía radicalmente, ya que a sus objetivos habituales se añaden los que le corresponden como recurso teatral. Consiguientemente, los diferentes géneros ven notablemente enriquecidos sus cometidos.

Formalmente, los géneros intercalados en los dramas de Lope conservan -no podía ser de otro modo en un discurso entrecomillado- los rasgos linguíísticos que les son propios. Cada enunciado concreto se elabora de acuerdo con la retórica de su género. Es éste el que deter-

mensajeros de amores). En este sentido, habría que mencionar, principalmente, $\mathrm{La} \mathrm{Ce}$ lestina -obra por que el autor siente especial predilección-y el Arte de amar de Ovidio. Para los géneros líricos no hay que descartar tampoco la fuerte asociación entre lo epistolar y la expresión amorosa, producto, sobre todo, del intenso cultivo de la novela sentimental.

so Dice el autor: "Los géneros primarios que forman parte de los géneros complejos se transforman dentro de estos últimos y adquieren un carácter especial: pierden su relación inmediata con la realidad y con los enunciados reales del otro, por ejemplo, las réplicas de un diálogo cotidiano a las cartas dentro de una novela, conservando su forma y su importancia cotidiana tan sólo como partes del contenido de la novela, participan de la realidad tan sólo a través de la totalidad de la novela, es decir, como acontecimiento artístico y no como suceso de la vida cotidiana". ("El problema...", op. cit., p. 250).

51 Servir a señor discreto, LII, p. 72. 
mina la organización del material y, consiguientemente, el que orienta tanto al emisor en su producción como al destinatario en la comprensión. Excepción hecha de la expresividad, el material lingüístico mantiene su disposición original, sus resonancias sociales e ideológicas e incluso -en el plano literario- la impronta del género, escuela o generación que lo utilizó anteriormente ${ }^{52}$. Se trata de un hecho evidente en los géneros de la comunicación cotidiana, pero es particularmente relevante en los dominios de la literatura.

3.2. En el teatro de Lope los géneros de carácter lírico forman parte, normalmente, de un complejo proceso amoroso, marcado por el signo negativo de las relaciones entre los amantes: el amor no es siempre correspondido, o se encuentra con la oposición de terceros ${ }^{53}$.

Dicho proceso tiene su propio discurso. En él aparecen una serie de figuras ${ }^{54}$, que evidencian tanto su complejidad intrínseca como las peculiaridades estilísticas. Dentro de este proceso las distintas figuras tienden a representar tanto la situación del amante como la visión que éste tiene del amado. El amante es un ser marcado por el sufrimiento que le ocasiona la ausencia del ser amado o por las dificultades que encuentra para conseguir su amor ${ }^{55}$. Por este motivo, la vida deja de tener sentido para é $1^{56}$ y se abandona por entero a su destino ${ }^{57}$. Su amor es tan fuerte que se considera esclavo del ser amado y prisionero del amor $^{58}$. Experimenta una imperiosa necesidad de comunicación, de contacto, y para lograr sus propósitos no duda en recurrir al engano ${ }^{59}$. Envía regalos y ayuda material a la otra parte ${ }^{60}$; utiliza objetos

52

Cfr. M. Bajtín: “Du discours romanesque”, op. cit., p. 141. El autor llega a decir que toda palabra lleva asociados sus contextos (ibid., p. 114).

53 Cfr. V. Sklovski: "La construcción de la nouvelle y de la novela", ed. T. Todorov, Teorta de la literatura de los formalistas rusos (Buenos Aires: Signos, 1970); B. Tomachevski: "Temática", ibid., p. 205. También, T. Todorov: Literatura y significación (Barcelona: Planeta, 1971), pp. 83ss.

54 La descripción más completa de este proceso se debe a Roland Barthes: Fragments d'un discours amoureux (París: Seuil, 1977).

5s La mayor virtud de un rey, XII, p. 637; El desconfiado, IV, p. 494.

56 Los embustes de Celauro, XI, p. 97; El caballero de Olmedo, XXXIV, p. 377; El mármol de Felisarda, t. 269 pp. 342-43; El cuerdo en su casa, XI, p. 561; El grao 269; La niña de Plata, XXIV, p. $282 \ldots$

57 El duque de Viseo, XLI, p. 440; Belardo el furioso, XIII, p. 77; El ruiseñor de Sevilla, t. 245 , p. $105 \ldots$

58 El acero de Madrid, XI, p. 366; El despertar a quien duerme, XI, p. 740; Quien ama no haga fieros, XXIV, p. $405 \ldots$

59 El castigo del discreso, IV, p. 213.

to La pobreza estimada, XXXIV, p. 158; La mal casada, XXXIV, pp. 293-94; Amar sin saber a quien, XXXIV, p. 446; La villana de Getafe, X, p. $381 \ldots$ 
-bandas, listones, etc. - para facilitar el reconocimiento o como manifestación externa de su amor ${ }^{61}$. Acepta con docilidad las condiciones que le impone el ser amado y expresa su júbilo por el encuentro; suplica piedad, confiesa su demencia ... ${ }^{62}$.

El ser amado, por el contrario, es visto como una persona cruel y vengativa -un verdadero tirano-, cuyo corazón no tiene nada que envidiar al mármol o a la nieve en dureza y frialdad ${ }^{63}$.

La retórica del proceso amoroso -tal como es presentado por Lope- responde preponderantemente a la concepción del amor difundida por el petrarquismo, bien es verdad que tamizada por la tradición española ${ }^{64}$. Confirman esta impresión las numerosas imágenes empleadas por los amantes para representar sus variables estados de ánimo: enfermedad o muerte frente a vida, frio hielo o nieve frente a fuego abrasador, noche frente a día, sol o cielo, crueldad, venganza, generosidad, dulzura ...65.

3.3. El acto de la recepción de los géneros intercalares presenta peculiaridades dignas de reseñarse. No todos los escritos son objeto de una lectura íntegra por parte del destinatario; algunos -realmente pocos- se leen sólo parcialmente y otros -menos todavía- únicamente se mencionan. Este hecho, sin embargo, no significa en modo alguno una aminoración de su eficacia dramática, sino, frecuentemente, todo lo

61 El caballero de Olmedo, XXXIV, p. 370 y 377-78; Amar servir y esperar, III, p. 226; La pastoral de Jacinto, XIII, p. 39.

62 La cortesía de España, IV, p. 338; Resistencia honrada y la Condesa Matilde, IX, p. 224; La ocasión perdida, VIII, p. 217; El hijo de Reduán, t. 214, pp. 298-99 y 303; La discreta enamorada, t. 247, p. 168; El cuerdo en su casa, XII, p. $561 \ldots$

63 Los embustes de Celauro, XII, p. 97; El maestro de danzar, XXXIV, p. 71; El caballero de Olmedo, XXXIV, pp. 377-78; La buena guarda, t. 187, p. 66; El cuerdo en su casa, $\mathrm{XI}, \mathrm{p} .561 \ldots$

64 Sobre el petrarquismo de Lope ver D. Alonso: Poesía española (Madrid: Gredos, 1971), pp. 431 ss. Tampoco ofrece hoy dudas la presencia de Petrarca en La Celestina (cfr. A.D. Deyermond: The Petrarchian Sources of 'La Celestina' -Oxford: Oxford University Press, 1961). Es preciso señalar, sin embargo, que no todos los géneros líricos presentes en el teatro de Lope son adscribibles al petrarquismo; algunos sobresalen por su intenso conceptismo (cfr. El perro del hortelano, XXIV, pp. 344-45; El pricipe perfecto-segunda parte-, LII, pp. 120-21; La prueba de los ingenios, t. 246, p. 315...)

Ver obras citadas en notas anteriores. Habría que añadir únicamente en la importancia que adquiere el sentido de la vista en la relación amorosa (cfr. El perro del hortelano, XXIV, pp. 344-45; El maestro de danzar, XXXIV, p. 71; La pobreza estimada, LII, p. 142; El caballero de Olmedo, XXXIV, p. $370 \ldots$ 
contrario $^{66}$. Otra particularidad del acto de recepción es la lectura intermitente, que sirve de pretexto a los comentarios del destinatario o de los presentes ${ }^{67}$. En este caso la capacidad dramática del escrito se ve notablemente potenciada, ya que atiende, simultáneamente, a varios cometidos: provoca una reacción especial en el receptor -con frecuencia, éste rompe el escrito o repite varias veces su lectura-, acentúa la comicidad o el dramatismo y, sobre todo, contribuye poderosamente a la intriga ${ }^{68}$.

Dentro del escrito, por lo demás, es de suma importancia la consideración de la diferencia entre los aspectos material, literal y referencial (particularmente, los continuos desajustes entre los dos últimos) ${ }^{69}$. En efecto, en los dramas de enredo -la mayoría de los analizados- se aprecia una frecuente confrontación entre los sentidos literal y referencial. La significación del escrito varía muy notablemente, ya se considere en sí mismo -en sus propios términos-, o desde la perspectiva general del drama. Es una propiedad de los géneros intercalares presentes en las comedias de enredo, ya que en este caso quedan subordinados a la intriga. Así, en Dómine Lucas el juramento -género que, de suyo exige la máxima seriedad-por el que Lucrecia se declara esposa de Lucas resulta ser, finalmente, un engaño ${ }^{70}$. Lo mismo ocurre con la oda (ya mencionada) de Servir a señor discreto. Su carácter noble se desvirtúa al ser utilizado como recurso cómico ${ }^{71}$.

Un caso extremo es el que aparece en Los prados de León y en La inocente Laura. En el primer caso se imita la letra y firma de Nuño con la finalidad de enemistarlo con el rey y el enunciado, por consiguiente, no se ajusta en modo alguno a la realidad de los hechos ${ }^{72}$. En La inocente Laura es Ricardo el que, en connivencia con Roberto y Leonarda, inspira las cartas que éstos remiten al duque (su contenido es, obviamente, falso) ${ }^{73}$. Algo muy similar se produce en El valor de las mujeres y en El maestro de danzar ${ }^{74}$. En todos estos casos el sentido literal se ve traicionado por el contexto.

66 El duque de Viseo, XLI, p. 440; El maestro de danzar, XXXIV, p. 85; Quien ama no haga fieros, XXIV, p. $446 \ldots$

67 La pobreza estimada, LII, p. 142; La mocedad de Roldán, XXIX, Pp. 15-16; El caballero de Olmedo, XXXIV, p. 377; La francesilla, V, p. $667 \ldots$

68 La Estrella de Sevilla, XXIV, p. 146; El perro del hortelano, XXIV, pp. 344-46; La moza del cántaro, XXIV, p.. 549. Un caso peculiar es el de El maestro de danzar, XXXIV, p. 85. El marido -que ya desconfía de su mujer- ve confirmadas las sospechas al recoger del suelo los fragmentos de una carta. No puede recomponer todo el texto, pero las pocas palabras que consigue reunir son suficientes para avivar sus celos.

${ }^{69}$ T. Todorov: Literatura y significación (Barcelona: Planeta, 1971), pp. 24 ss.

70 XXIV, p. 63

71 LII, p. 72.

72 LII, p. 443.

${ }^{73}$ LII, pp. 485-486.

$74 \mathrm{X}$, p. 116. 
El fenómeno contrario aparece en El perro del hortelano ${ }^{75}$. Tanto Diana como Teodoro simulan dirigir a otros las cartas que ellos saben dirigidas a sí mismo. Se trata de un simulacro perfecto del diálogo real. En todos los casos reseñados -y en muchos más- el contenido de los diferentes enunciados es viciado -contradicho incluso- por la realidad efectiva de los hechos. El autor ironiza y parodia continuamente los géneros que introduce en el drama. Es una prueba manifiesta de su debilidad ante la expresividad autorial. La distancia, en definitiva, entre los aspectos literal y referencial evidencia la intensa perversión a que son sometidos los géneros intercalarares por parte del escritor ${ }^{76}$.

La importancia del aspecto material es manifiestamente inferior. Pocos textos ofrecen peculiaridades dignas de mención. El ejemplo más ilustrativo aparece en El maestro de danzar: la carta que Tebano recoge del suelo está hecha pedazos y su recomposición resulta casi imposible. Este hecho condiciona de modo notable la interpretación que el personaje atribuye a las pocas palabras que consigue leer ${ }^{7}$.

En cuanto partes integrantes del proceso comunicativo y elementos estrechamente vinculados al aspecto material es preciso mencionar dos factores más: emisor y destinatario ${ }^{78}$. Respecto del primero hay que reseñar su ausencia formal en muchos de los generos intercalares. A pesar de la carencia de firma, en modo alguno puede decirse que se trata de escritos anónimos. El emisor se hace explícito, de manera muy especial, en los géneros nobles o de carácter serio: pactos ${ }^{79}$, órdenes ${ }^{80}$, sentencias ${ }^{81}$, juramentos ${ }^{82}$, bandos ${ }^{83}$, cartas de recomendación ${ }^{84}$ ... Con todo, su presencia puede advertirse también en no pocos géneros íntimos (en particular, lo que tienen que ver con la comunicación amorosa,) aunque en ellos predomina el emisor implícito ${ }^{85}$. En los gé-

75 XXIV, pp. $344-45$ y 346.

76 Resultan sumamente esclarecedoras al respecto las palabras de Bajtín: “... enunciados ajenos pueden ser introducidos directamente al contexto de un enunciado, o pueden introducirse sólo palabras y oraciones aisladas que en este caso representan los enunciados enteros, y tanto los enunciados enteros como palabras aisladas pueden conservar su expresividad ajena, pero también puede sufrir un cambio de acento (ironía, indignación, veneración, etc.). Los enunciados ajenos pueden ser representados con diferente grado de revaluación..." ("EL problema...", p. 281). XXXIV, p. 85 Cfr. La vengadora de las mujeres, XIII, p. 615; El casamiento en la muerte, XVII, p. 59 El mayor imposible, XXXIV, p. 484.

81

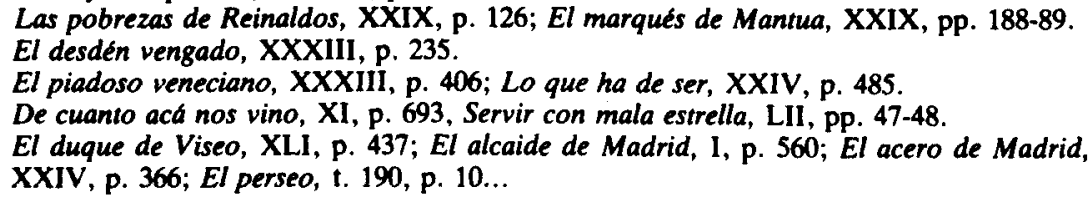


neros familiares o íntimos la presencia formal del emisor no es ni siquiera necesaria; el destinatario deduce fácilmente, por el contexto, quien es la persona que le escribe. Por lo demás, el anonimato tiende a garantizar de alguna manera el carácter confidencial de la comunicación entre los amantes ${ }^{86}$. En muy raras ocasiones se trata de auténticos anónimos ${ }^{87}$.

Las imágenes del emisor son tan variadas como diversas las situaciones en que se halla involucrado en la vida real. También cuenta, obviamente, la enorme diversidad de caracteres entre las personas. En el teatro de Lope los emisores más frecuentes son los amantes, el padre o el pariente y el rey o noble. Por lo general, los amantes confiesan su amor, reprochan a la otra parte su indiferencia, lamentan su ausencia, prometen fidelidad, buscan por todos los medios el encuentro con el ser querido .... ${ }^{88}$. El padre -o pariente- aparece como consejero, confidente y valedor en la adversidad ${ }^{89}$. El rey, el Papa o el noble adoptan, generalmente, una imagen autoritaria: dictan ordenes o sentencias, establecen pactos, amenazan, ofrecen recomponsas ...90.

Si la presencia o ausencia del emisor condiciona fuertemente la recepción del mensaje $-y$, en el caso del teatro, presenta importantes repercusiones dramáticas- al destinatario se le reserva un papel más importante todavía. Supuesto que todo enunciado busca por necesidad una respuesta -o reacción- en la persona a la que va destinado, ésta se erige en un punto de referencia fundamental para el emisor. Y lo que es más importante: condiciona los rasgos formales del enunciado en particular, su estilo y composición. Todo el proceso de enunciación aparece volcado sobre el receptor. El emisor se forma en su mente una imagen de su destinatario y toma en consideración todos aquellos aspectos que pueden ser relevantes para la comunicación: nivel socioeconómico, estado anímico, grado de conocimiento de los asuntos tratados, situación concreta en que se encuentra, etc. Por todo esto, puede decirse que, paralelas a las imágenes del emisor, caminan las imágenes del destinatario ${ }^{91}$.

Así se explica, por ejemplo, la enorme variedad de títulos empleados en los distintos géneros intercalares. Estos van desde los registros

86 El castigo del discreto, IV, pp. 198-99; El desconfiado, IV, p. 482; El caballero de Olmedo, XXXIV, pp. 377.78...

87 La pobreza estimada, LII, p. 161 (en este caso la dama adivina por el contexto quién es el emisor). Con todo, el ejemplo más representativo -ya que aparece vinculado a la denuncia- se ofrece en $E l$ valor de las mujeres, X, p. 110.

Ver ejemplos citados en las notas (6), (7), (10), (12), (13), (14)...

89 Cfr. notas (8). (15) y (21).

${ }^{9}$ Cfr. notas (14), (24), (35) y (37). El Papa, a su vez, aparece como un censor severo. (cfr. La varona castellana, XIX, p. 18).

9 Ver Bajtín, op. cit., pp. 285 ss. 
más formales -Vuestra Majestad, vuestra Alteza; Duque de Alba, mi primo; amados hijos en Cristo; $A$ todos los Príncipes y a todos mis vasallos; Salud, a vos noble senado y República veneciana..., utilizados por el Rey o el Papa para dirigirse a sus subordinados ${ }^{92}$ - a los más familiares -padre, hermano mio, sobrino, hijo... ${ }^{93}$ - e intimos -lumbre mía, señora mia, mi bien, ingratisimo Belardo, Leonor mía, alma y luz de mi deseo, hermosa Lucinda... ${ }^{94}$. En este sentido merece señalarse el estilo eminentemente convencional, propio de los géneros que pertenecen a la esfera oficial, frente al más flexible y creativo de los familiares e íntimos ${ }^{95}$. Hay que destacar, también, el carácter transparente de la información contenida en los primeros frente a la relativa opacidad -información a medias, lectura entre líneas- propia de la comunicación amorosa ${ }^{96}$.

Por otro lado, las imágenes del destinatario hay que deducirlas de las palabras del emisor, de los objetivos perseguidos: ablandar un corazón indiferente, recordar una promesa a una persona tal vez olvidadiza, exhortar y orientar al hijo sobre lo perniciosas que pueden resultar las malas compañias, humillar al bravucón...97. Con este fin el emisor recurre al tono ardiente, quejoso o compasivo del enamorado, al cariñoso y persuasivo del padre, al severo o amenazador del Rey o el Papa, al frío e impersonal de las comunicaciones oficiales $\ldots{ }^{98}$.

Antes de poner punto final a este largo apartado sólo dos palabras sobre otra posible consideración de los géneros intercalares. A causa precisamente a su incorporación a un contexto eminentemente dialógico, los géneros acogidos a la forma de escrito pueden equipararse adecuadamente a la modalidad general de discurso imperante en el drama. El escrito se presenta como enunciado-respuesta o enunciado-interpelación -o ambos al mismo tiempo- y la voz del mismo no difiere fundamentalmente de las otras voces del drama más que en la forma de manifestarse. El emisor de estos enunciados es un personaje más y su discurso -aunque sometido a unos códigos distintos de los que rigen la comunicación oral- equiparable al del resto de los personajes (esto es,

92 La vengadora de las mujeres, XIII, pp. 615, 642-43; Ursón y Valentín, XXIX, p. 450; El Ramírez de Arellano, t. 212, p. 275; Las pobrezas de Reinaldos, XXIX, p. 126; La santa liga, t. 224, p. $245 \ldots$

El valeroso catalán, XIX, p. 126; La pobreza estimada, LI, p. 149; La obediencia laureada, LII, p. 181; Los prados de León, LII, p. 446...

El acero de Madrid, XI, p. 366; Belardo el Furioso, XII, p. 77; El desconfiado, IV, p. 494; El ruiseñor de Sevilla, t. 249, p. $105 . .$. Cfr. Bajtín, op cit., pp. 268-269.

96 Cfr. Apartados 2.1, 2.2, 2.5, 2.20. A ellos habría que añadir aquellos géneros que, por su propia naturaleza, se apoyan en la opacidad del mensaje: la profecía, el enigma, la alegría... (cfr. apartados $2.17-2.20$ ).

97 Ver ejemplos citados en notas (5), (6), (12), (13), (17), (21), (22).

98 Ejemplos en apartado 2. 
discurso directo, dramatizado, en vez de discurso leído). El emisor se incorpora al drama por medio de la lectura del enunciado.

La naturaleza dialógica del escrito se evidencia, además, por el carácter interpelativo del mensaje: lo que trata de conseguir es siempre la reacción del personaje. Esta se da indefectiblemente -aunque no siempre de modo inmediato-, bien bajo la forma de comentarios (que provocan la interrupción de la lectura), bien bajo forma de acción ${ }^{99}$.

El teatro de Lope ofrece abundantes ejemplos de la posibilidad de considerar el escrito -y la carta, en particular-como variedad del estilo directo. Desde luego, sus consecuencias en cuanto recursos literarios son muy similares ${ }^{100}$. Ahora bien, para evitar equívocos, conviene hacer algunas precisiones. A diferencia del estilo indirecto en la lengua de uso -en que el hablante se limita a reproducir exactamente lo dicho por otro- la creacción artística va mucho más lejos: incorpora -en este caso a través de la cita textual- los distintos géneros de la comunicación escrita cotidiana (y cultural, por supuestso), pero éstos son objeto de una representación literaria ${ }^{101}$. En el teatro de Lope la actitud del autor hacia los distintos géneros intercalares es, formalmente, de máximo respeto, ya que se mantiene en su integridad el discurso transmiti$\mathrm{do}^{102}$. Ahora bien, dado que la labor del escritor consiste precisamente en someter las lenguas incorporadas a un procesp de estilización, esto pone en entredicho, y ya desde el principio, el supuesto contrato de literalidad del estilo directo con el discurso original ${ }^{103}$. Por paradójico que pueda parecer, es precisamente el discurso entrecomillado el más permeable a la expresividad ajena -en otras palabras, el más intensamente dialógico ${ }^{104}$.

99 Bajtín afirma que es precisamente en el discurso escrito donde se produce de modo más claro la respuesta de acción retardada: "...tarde o temprano lo escuchado y comprendido activamente resurgirá en los discursos posteriores o en al conducta del oyente. Los géneros de la compleja comunicación cultural cuentan precisamente con esta activa comprensión de respuesta de acción retardada. Todo lo que estamos exponiendo aquí se refiere, con las correspondientes variaciones y complementaciones al discurso escrito y leído" ("El problema...", pp. 257-258).

100 Ver T. Todorov, op. cit., pp. 52-55.

101 Cfr. M. Bajtín: “Du discours...", op,. cit., 156 ss., y “El problema...”, op cit., pp. 253-254.

112 Se insertaría dentro de lo que algunos miembros de la escuela de Bajtín denominan estilo lineal (Cfr. V.N. Volosinov: Marxism and the Philosophy of Language-New York: Seminar Press, 1973-, pp. 119-120).

103 G. Genette afirma que en el ámbito de la literatura este supuesto contrato no se cumple realmente, ya que el enunciado en este caso carece de verdadero original (Cfr. Nouveau discours du récit - París, Seuil, 1983 - pp. 54 ss).

Ver Bajtín: "El problema...", op. cit., p. 283. 


\section{Funciones De Los Generos Intercalares Dentro Del Teatro DE LOPE ${ }^{105}$}

Vistos ya los diferentes tipos de géneros intercalares y sus rasgos formales, se trata ahora de considerar el cometido que desempeñan en cuanto recurso dramático. El análisis de las funciones reviste enorme importancia para comprender correctamente la naturaleza (eminentemente) subsidiaria de los géneros intercalares y, en el caso presente, para comprobar hasta qué punto resultan adecuadas las propuestas de M. Bajtín. Sólo desde una perspectiva funcional se justifica su presencia dentro de los dramas de Lope y se explican tanto los objetivos perseguidos por el autor como el momento dramático elegido para la incorporación.

Aun siendo todas igualmente importantes para el desarrollo del drama, se distinguen dos tipos generales de funciones: argumentales y subsidiarias. Las primeras podrían designarse también estructurales o temáticas -en el sentido formalista del término-, puesto que se encuentran estrechamente vinculadas a la organización del material dramático. En principio, puede decirse que cada Acto tiene sus funciones peculiares, aunque esta afirmación debe someterse a importantes restricciones. Las funciones subsidiarias, por el contrario, reciben esta denominación no por su carácter secundario, sino porque desempeñan cometidos que incumben a cada género intercalar, al margen de cuál sea su misión principal. Por su presencia constante, las funciones subsidiarias evidencian el carácter polivalente de los distintos géneros intercalares.

Las funciones principales se dividen, a su vez en dos grupos: puramente argumentales y caracterizadoras. Las primeras se corresponden, aunque con frecuentes desajustes, con la poética de cada acto dramático. Así, existe un buen número de escritos dentro del Acto I, cuya misión consiste, fundamentalmente, en introducir o revelar el problema general del drama. De una manera o de otra, todos los acontecimientos derivan de ellos. En este sentido, su contribución a la intriga es muy importante. El villano en su rincón ofrece un ejemplo bastante ilustrativo: el drama se complica ya desde el principio como consecuencia del interés real por conocer a la persona mencionada en la inscripción. El rey siente una enorme curiosidad por aquel hombre -Juan Labrador-, que vive ajeno por entero a todo lo que desborda los límites de su hacienda. Ni siquiera la proximidad del rey logra tur-

$105 \mathrm{El}$ análisis de las funciones se ha reducido, por obvias razones de espacio, a veintidós dramas. 
bar su placentera vida campestre. La inscripción, pues, no plantea en sí misma ningún problema, pero da lugar al conflicto central de la obra ya que el rey tratará por todos los medios de probar la veracidad de aquellas palabras. La inscripción es utilizada, en definitiva, para aislar al personaje protagonista y, también, para anticipar el nudo del dra$\mathrm{ma}^{106}$.

Algo similar ocurre en Servir a señor discreto ${ }^{107}$. El primer escrito contiene la negativa de Leonor a las pretensiones de don Pedro. Este rechazo provoca, sin embargo, una reacción de signo muy distinto a la deseada por la dama: en vez de marcharse, don Pedro decide permanecer en Sevilla y se propone hacer todo lo posible para lograr sus objetivos. Una vez más el escrito introduce un cambio en el rumbo seguido hasta ese momento por el drama. El escrito funciona en estos casos como factor desencadenante de conflictos ${ }^{108}$.

En El caballero de Olmedo, sin embargo, tanto el soneto de don Alonso como la respuesta de doña Inés no presentan en sí mismos ningún conflicto, pero anticipan realmente el más importante de todo el drama ${ }^{109}$. El soneto sirve para introducir formalmente un nuevo pretendiente de doña Inés. Los enfrentamientos posteriores entre don Alonso y don Rodrigo $-\mathrm{y}$, en último término, la muerte de aquél a manos de éste- proceden, de hecho, de las sospechas -más tarde confirmadas por otros indicios- que levantan los distintos mensajes escritos de doña Inés y su nuevo galán.

Otro ejemplo de la capacidad de los géneros epistolares con vistas a la complicación dramática se presenta en El maestro de danzar ${ }^{110}$. El billete en que Vandalino pide una cita a Florela da lugar -por medio, sobre todo, de los comentarios intercalados en la lectura- a un gran enredo. Florela desecha la idea de encontrarse a solas con el pretendiente, pero su hermana, recién casada, pide acudir a la cita en su lugar. Este hecho -incluido directamente por el billete-introduce una gran ambigüedad respecto de los sentimientos de las damas. Vandalino recibe el sí a sus pretensiones de labios de Feliciana, cuando él suppone estar hablando con Florela. Lo mismo le ocurre a Aldemaro: ve en peligro todos sus esfuerzos por conquistar a Florela, ya que las apariencias le inducen a creer que es ésta la que entretiene a Vandalino en la reja del jardín.

Esta capacidad del escritor para crear o anticipar conflictos se pone también de manifiesto en El perro del hortelano" "I".

IIK XXXIV, p. 139

117 Lll, p. 70 .

I0R Situaciones muy similares pueden encontrarse en El amigo hasta la muerte, LII. p. 327; El marqués de las Navas, LII, p. 504; Porfiando vence amor, XLI, p. 240...

1(x) XXXIV.p. 370.

110 XXXIV, p. 77.

111 XXIV, pp. $344-45,346$ y 354. 
La función principal de los géneros intercalares en el Acto II se corresponde en la mayoría de los casos con los cometidos asignados a esta parte del drama: la complicación, en particular. Esta función, sin embargo, adopta muy diversas formas: crea conflictos, acentúa el enredo, provoca el clímax dramático y, en todo momento contribuye intensamente a la intriga.

La Estrella de Sevilla contiene las mejores muestras del empleo escrito al servicio de la complicación dramática ${ }^{12}$. Los tres escritos -dos órdenes y un billete- tienen como destinatario a Sancho Ortiz de las Roelas y sitúan a este personaje ante un dilema de muy difícil solución: respetar la palabra del rey -y perder, consiguientemente, a la dama de la que está enamorado- o desobedecer el mandato real y quedar como un hombre sin honor. Sancho se encuentra, en definitiva, entre el amor y la obediencia y elige un camino difícil, pero acorde con los códigos del honor imperantes en la época ${ }^{113}$. Los tres escritos -en particular, el tercero- crean el verdadero clímax de la obra. A través de ellos se perfila, además, el carácter trágico de la decisión adoptado por Sancho. Los escritos recogen y condensan-más que crean-toda la conflicitividad que se vive en el drama en ese momento.

En la mayoría de los dramas de Lope, sin embargo, el conflicto surge directamente del contenido de los géneros intercalares, de manera especial cuando es falso. Así ocurre, por ejemplo, en Los prados de León ${ }^{114}$, La inocente Laura ${ }^{115}$, El maestro de danzar ${ }^{116}$, Dómine Lucas $^{117}$, etc. Es un hecho particularmente evidente en Los prados de León. En este drama se insertan dos escritos. en el primero Nuño, villano ennoblecido por el rey, aparece como traidor a la corona. Se trata de una estratagema de don Arias, el cual, ayudado por Tristán y Ordoño, ha imitado la letra de Nuño con la única finalidad de indisponerlo con el rey. El segundo presenta un carácter antitético respecto del anterior ${ }^{118}$. En él se revela la verdadera identidad de Nise, villana y amada de Nuño. Este escrito constituye una buena muestra de la capacidad del escrito para desempeñar funciones contrarias. En efecto: la confidencia se presenta, en principio, como solución a los problemas de los dos amantes: por su nobleza la dama queda ahora equiparada a Nuño y éste, presumiblemente, ya no tendrá que casarse a su pesar con doña Blanca. Ahora bien, la revelación se produce en el preciso

\footnotetext{
112 XXIV, pp. 145-46.

113 Ibid., p. 146.

114 LII, p. 443.

115 LII, pp. $385-486$.

116 XXXIV, p. 85.

117 XXIV, p. 63.

118 Loc. cit., p. 446.
} 
momento en que Nuño pierde el favor real, es desposeído de su nobleza y tiene que regresar a la aldea. Cuando llega se encuentra con que Nise ha abandonado el lugar para residir en la corte.

Consiguientemente, el escrito contribuye a la creacción de un nuevo conflicto y todavía se le puede atribuir una función más: facilita indirectamente la solución final, ya que del escrito depende la partida de Nise hacia la corte y Nise es, también, la causa inmediata de la discusión entre don Arias y Tristán. Disgustado éste con don Arias por sus pretensiones respecto de Nise, revela al rey la verdad sobre la autoria del primer escrito. Como consecuencia, Nuño es rehabilitado.

El carácter positivo o negativo de los géneros intercalares depende, pues, de la situación dramática y, por supuesto, del personaje. Lo que en un momento dado aparece marcado por el signo de la conflictividad puede resultar, desde la perspectiva general del drama, un factor decisivo para la solución. Y lo mismo cabe decir de los personajes; la recepción del mensaje reviste distinto signo de acuerdo con el papel del destinatario: para unos supone la salida de una situación difícil y para otros la aparición de un nuevo obstáculo. Es más: los personajes inmeditamente perjudicados por el contenido de un escrito pueden ser a la larga los más beneficiados y viceversa. Así ocurre, por ejemplo, en La inocente Laura: las falsas acusaciones de Ricardo, Roberto y Leonarda contra el Duque terminan volviéndose en el último acto contra ellos ${ }^{119}$. La situación es todavía más clara en la Pobreza estimada; la respuesta del padre cautivo respecto del marido ideal para Dorotea soluciona un conflicto importante, pero crea otro. La escasez de recursos materiales obliga a Leonido a abandonar temporalmente el hogar $y$, consiguientemente, Dorotea que sola y a merced de las asechanzas de Ricardo ${ }^{120}$.

En otros casos, por el contrario, el escrito es incorporado por sus vitualidades respecto de la intriga ${ }^{121} \mathrm{o}$, simplemente, para torcer el rumbo de la acción ${ }^{122}$. Finalmente, el escrito puede servir para anticipar acontecimientos, que tendrán especialmente relevancia en el posterior desarrollo del drama ${ }^{123}$.

La función principal de los géneros intercalares en el Acto III se ajusta plenamente a su poética: introducen $y$, con más frecuencia, preparan el desenlace. El ejemplo de la Estrella de Sevilla es suficiente-

LII, pp. 485-86. Algo parecido se observa en Virtud, pobreza y mujer -ibid., p. 223. La carta en que Isabel promete ayuda a Carlos da lugar a una nueva complicación: Carlos quedará libre, si consigue que Fátima acepte a Alí.

LII, p. 152.

121 El maestro de danzar, XXXIV, p. 85.

122 La mayor virtud de un rey, XLI, p. 87; El perro del hortelano, XXIV, p. 349.

123 El caballero de Olmedo, XXXIV, p. 377. 
mente ilustrativo al respecto: la condena a muerte de Sancho por parte de los alcaldes da lugar a que el rey, arrepentido, confiese su maldad $^{124}$. También es palmaria la contribución del escrito a la solución del problema en El duque de Viseo, entre otros ${ }^{125}$. Tanto las dos cartas como el horóscopo -magnífico ejemplo éste de la eficacia de un escrito que no es leído, sino simplemente mencionado- tienen como misión aumentar los celos y las sospechas del rey respecto de las pretensiones del duque. El contenido de la primera es realmente intrascendente, pero permite al correo sorprender al duque representando el papel de rey en un improvisado juego con los villanos de su aldea (posteriormente el correo será obligado por el monarca a revelar todo lo que ha visto). En la segunda -remitida con carácter de urgencia por doña Elvira- la dama comunica al duque los deseos del rey de casarla rápidamente con don Egas. Este escrito tiene como consecuencia más inmedita el temerario regreso del duque a Lisboa, mientras -por una desgraciada equivocación suya- llega a manos del rey el horóscopo en el que se vaticina que será el futuro soberano de Portugal. Es desenlace -la muerte del duque- es preparado indudablemente por los escritos que aparecen en el último acto ${ }^{126}$. El autor se vale de ellos, por lo general, para provocar el clímax dramático o bien para reunir a todos los personajes que, por necesidad, han de participar en la solución definitiva.

3.2. Entre las funciones subsidiarias -las inherentes a cualquier escrito- destaca por su importancia la caracterizadora de personajes $y$, en menor medida, de ambientes. Es un cometido desempeñado por todos los géneros epistolares, aunque no todos lo llevan a cabo del mismo modo. En la mayoría de los casos se trata de una función complementaria; es la caracterización indirecta. Son muy pocos los ejemplos de escrito que tienen como misión principal la caracterización de personajes ${ }^{127}$. En estos casos el escrito adopta las formas de la descripción o la recomendación y aparecen, por lo general, en el Acto $1^{128}$.

Con relativa frecuencia el escrito caracterizador es utilizado como recurso para presentar formalmente a un determinado personaje -geneneralmente, protagonista. El caso posiblemente más representativo es

XXIV, p. 152.

125 La mayor virtud de un rey, XLI, p. 89; La obdiencia laureada, LII, p. 181; Servir con mala estrella, LII, p. 65; El villano en su rincón. XLI, pp. 149-50.

126 XLI, pp. 437 y 440.

Habria que exceptuar el ejemplo de La pobreza estimada -LII, p. 149-, que aparece en el Acto II (quizá porque en este caso la descripción se encuentra en el interior de otro género). 
el de El villano en su rincón: la descripción de Juan Labrador no sólo aporta los motivos caracterizadores del personaje, sino que, además, se corvierte en resorte de todo el quehacer dramático ${ }^{129}$. En otros casos, sin embargo, la presentación y caracterización -más o menos general- del personaje se vale del género de la recomendación. Es lo que ocurre, sin ir más lejos, en Porfiar hasta morir ${ }^{130}$ y Servir con mala estrella ${ }^{131}$.

De todos modos, la caracterización de los personajes es, como se ha dicho anteriormente, un cometido inherente a todo género epistolar $y$, consiguientemente, puede aparecer en cualquier acto. Por su propia naturaleza, todo escrito caracteriza al emisor-como responsable de ese acto comunicativo-, en no pocas ocasiones al destinatario y, menos frecuentemente, a terceros. Cuando se afirma que todo escrito caracteriza a su emisor quiere decirse que, de alguna manera, en él se refleja la expresividad -la imagen- del autor. Un buen ejemplo lo ofrece una vez más El perro del hortelano ${ }^{132}$. El papel de amores que Diana entrega a su secretario para su corrección antes de ser emitido es, en realidad, una sutil insinuación amorosa de la dama hacia el propio secretario. El papel permite entrever una de las cualidades que acompañan al personaje de Diana a lo largo de toda la obra: su enorme habilidad para darse a entender con medias palabras y, en definitiva, para controlar las situaciones a su favor.

Algo parecido puede decirse de El amigo hasta la muerte $e^{133}$.Los dos escritos del Acto I presentan -además de dar lugar al conflicto central del drama- a su emisor como amigo fiel y discreto, pues renuncia a su amada para evitarle complicaciones a su amigo don Bernar$\mathrm{do}^{134}$. Con todo, la importancia del escrito como factor subsidiario al servicio de la caracterización de los personajes se evidencia, principalmente, en aquellos géneros cuyo contenido es falso ${ }^{135}$.

Dramáticamente, el escrito adquiere mayor relevancia cuando contribuye a la caracterización del destinatario. En este caso la imagen del receptor no forma parte del contenido del escrito, sino que es provocada directamente por su recepción. A ella contribuyen poderosamente las peculiaridades del acto mismo de recepción -en particular,

\footnotetext{
129 XXXIV,p. 139.

130) XLI, p. 97.

131 LII, pp. 47-48.

132 XXIV, pp. 344-45

133 LII, p. 327.

134 Más ejemplos: Porfiando vence amor, XLI, p. 238; Porfiar hasta morir, XLI, p. 104; Virtud, pobreza y mujer, LII, p. 223...

135 La inocente Laura, LII, pp. 485-86; Los prados de Lebn, LII, p. 443; El valor de las mujeres, $\mathrm{X}, \mathrm{p} .116 \ldots$
} 
la entonación, la lectura única o repetida, y elementos extralingüísticos como el gesto, etc.

La Estrella de sevilla ofrece una buena muestra de lo dicho anteriormente: los memoriales que aparecen en el Acto I tienden, sobre todo, a evidenciar la arbitrariedad real, ya que el soberano pretende entregar el cargo de general de campo a la persona que menos lo merece $-\mathrm{e}$ incluso contra su voluntad- ${ }^{136}$. En el mismo sentido se orientan los escritos segundo y cuarto; evidencian -el último a través, sobre todo, de los monólogos que siguen a cada lectura de la orden del rey- el enorme conflicto vivido por el personaje y su perplejidad ante la decisión más conveniente. El fatalismo y la tragicidad que acompañan al personaje de Sancho se derivan en gran medida del contenido de los escritos ${ }^{137}$. Por el contrario -la sentencia- da lugar a un cambio radical en la imagen del rey, que se arrepiente de su comportamiento ${ }^{138}$.

Planteamientos similares -aunque en un contexto muchos menos dramático- se observan en La pobreza estimada. Todos los escritos que tienen a Dorotea como destinataria se proponen evidenciar su inocencia y fidelidad. Particularmente interesante es el que aparece en el Acto I: su lectura se interrumpe tres veces para dar lugar a las exclamaciones y comentarios del personaje ${ }^{139}$. A través de ellos se revela la firma decisión de la dama de mantener limpia su honra a cualquier precio y, al mismo tiempo, quedan al descubierto sus vacilaciones ante los embates del amor. Los dos últimos escritos -ya en el Acto IIIacentúan, sobre todo la fidelidad de Dorotea a Leonido, a pesar de las adversidades ${ }^{140}$.

Menos frecuente -pero no menos importante- es el cometido del escrito en cuanto caraterizador de sensaciones o ambientes. Así ocurre, por ejemplo, en $E l$ duque de Viseo. La última comunicación entre el duque y su dama contribuye a crear en el espectador el presentimiento de que el regreso del primero a Lisboa tendrá un desenlace trágico ${ }^{141}$. Función muy parecida cumple el último escrito de El caballero de $\mathrm{Ol}$ medo ${ }^{142}$. También aquí el contexto dramático en que se insertan la petición de regreso del caballero y el anuncio de la próxima visita del rey a Medina está cargado de presagios negativos. El carácter premonitorio de las cartas resulta indudable.

\footnotetext{
136 XXIV, p. 139.

137 XXIV, p. 146.

138 lbid., p. 152.

139 LII, p. 142.

146 lbid., pp. 158 y 161 .

141 XLI, p. 440.

142 XXXIV, p. 377
} 
3.3. Los géneros intercalares en el teatro de Lope cumplen también otras funciones importantes. Entre ellas destaca, en primer término, la de informar. Es un cometido que le compete por el carácter sígnico del mensaje. Ahora bien, frente al teatro contemporáneo el de Lope presenta una particularidad reseñable: el endocentrismo de la información que aporta el enunciado. Con muy pocas excepciones ${ }^{143}$ -al menos, en el corpus que sirve de base a este trabajo- los escritos informan únicamente al personaje-destinatario. Bien porque el asunto de la carta ha sido discutido o mencionado en escena, bien por el contexto dramático, los géneros epistolares no aportan información alguna al espectador. El espectador de Lope es una persona enterada. Este hecho aminora sensiblemente la eficacia de los escritos respecto del espectador (aunque no en todas las circunstancias) ${ }^{144}$. Respecto del espectador, pues, el escrito es en la mayoría de los casos un elemento redundante.

Más importante que el cometido informativo $-\mathrm{y}$ esto confirma la impresión de que los géneros intercalares forman parte del argumentoes la labor sintetizadora y dinamizadora del escrito. Su misión consiste, fundamentalmente, en recoger, condensar y potenciar elementos del drama presentados anteriormente. Los géneros intercalares constituyen, como acaba de verse en las páginas anteriores, un revulsivo tan fuerte que, con bastante frecuencia, dan lugar al conflicto central de la obra. En cualquier caso, combaten eficazmente la inercia del drama e imprimen coherencia a su desarrollo. En este sentido, conviene recalcar que los géneros epistolares representan -al menos, en el caso de Lope- una gran economía: facilitan el ahorro de otros recursos dramáticos más morosos o automatizados.

Una función más -ésta puramente escénica- es el extrañamiento ${ }^{145}$. El escrito irrumpe en la escena como un elemento anómalo y extraño y, como tal, reclama tanto la atención del personaje como la del espectador (respecto de éste por la forma de presentarse, no por el contenido). Supone un abandono -siquiere moméntaneo- de los gestos del lenguaje oral para acogerse a los derivados de la lengua escrita. La

143 La más clara aparece en Los prados de León, LII, p. 446. La carta revela un secreto importante respecto de la verdadera identidad de Nise. Otro ejemplo bastante ilustrativo se presenta en Servir a señor discreto, LII, p. 70 . Por encontrarse casi al comienzo del drama, el billete informa al mismo tiempo al destinatario y al espectador, si bien es verdad que éste puede intuir por el contexto el signo negativo de la respuesta de la dama.

Habría que exceptuar aquellos escritos cuyo contenido es falso. Por ejemplo, Los prados de León, LII, p. 443.

145 Uso el término en el sentido en que es habitual dentro del Formalismo Ruso (cfr. $V$. Sklovski: "El arte como artificio", ed. T. Todorov, Teoría de la Literatura de los formalistas rusos -Buenos Aires: Signos, 1970-, pp. 55-70). 
fluidez del coloquio se ve interrumpida por la actitud esencialmente monológica que implica la lectura. Externamente, el personaje tiene que concentrarse en los signos gráficos del escrito y suspender su parlamento. Como consecuencia, el drama sufre un parón momentáneo, pero la atención del espectador crece en proporción inversa, ya que no quiere perderse el contenido de un mensaje que adivina importante, a juzgar por la forma de presentarse. El escrito constituye, pues, un poderoso efecto escénico: provoca la expectación y, consiguientemente, contribuye a la intriga.

Por último, los géneros intercalares llevan a cabo otro cometido relevante (aunque ya mencionado anteriormente): acentúan el plurilingüismo del discurso teatral y contribuyen a evidenciar la dimensión también plural de la realidad social. Entablan un diálogo intenso con las demas lenguas del drama y, en particular, con la lengua representante del escritor. Esta lengua crea un fondo dialógico en el que resuenan de una determinada manera -siempre condicionadas por la expresividad del autor- las voces ajenas. Dentro del teatro de Lope los distintos géneros contribuyen a evidenciar el carácter poliédrico de la realidad linguística $y$, en último término, la dimensión plural de la realidad social.

4. De lo dicho anteriormente se infieren consecuencias importantes a propósito de los géneros intercalares $\mathrm{y}$, también, respecto de la validez del método empleado.

En cuanto al primer punto, es preciso señalar que la propuesta de Bajtín permite comprender adecuadamente la naturaleza y función de esos elementos marginales respecto del discurso principal, que son los géneros intercalares. Su consideración genérica facilita tanto la explicación del origen como el fuerte enraizamiento social de los distintos enunciados. Frente a la concepción tradicional, que no ve en los escritos intercalados en el teatro más que puros elementos ornamentales, la hipótesis de Bajtín hace hincapié en su enorme capacidad al servicio de la expresividad del autor. En el caso presente resulta innegable que los géneros intercalares desempeñan cometidos de primera magnitud dentro del drama y también que el género es completamente irrelevante para la función que se le asigna.

Por otra parte, la afirmación por parte de Bajtín del carácter esencialmente dialógico del discurso literario -excepción hecha de los géneros poéticos- ha hecho posible el descubrimiento de multitud de lenguas donde se suponía la existencia de una sola y, consiguientemente, la enorme variedad de estilos que ello conlleva. En este sentido, la perspectiva de Bajtín resulta enormemente esclarecedora, ya que permite integrar dentro del mismo paradigma todos los elementos que andaban dispersos en las demás propuestas. 